\title{
Tumor Necrosis Factor Inhibitor Discontinuation in Patients with Ankylosing Spondylitis: An Observational Study From the US-Based Corrona Registry
}

Philip J. Mease · Désirée van der Heijde · Chitra Karki •

Mei Liu · Yujin Park · Jeffrey D. Greenberg

Received: August 17, 2018 / Published online: October 23, 2018

(C) The Author(s) 2018

\section{ABSTRACT}

Introduction: Tumor necrosis factor inhibitors (TNFis) have shown efficacy for the treatment of ankylosing spondylitis (AS). However, many patients may discontinue or switch TNFis due to lack of effect or adverse events. As biologics with alternative mechanisms of action become available for the treatment of AS, it is important to better understand the characteristics of patients who discontinue or have an inadequate response to TNFis to help inform treatment choices regarding initiating or switching to a biologic therapy. This study compared

Enhanced digital features To view enhanced digital features for this article go to https://doi.org/10.6084/ m9.figshare.7166189.

P. J. Mease $(\bowtie)$

Swedish Medical Center and University of

Washington, Seattle, WA, USA

e-mail: pmease@philipmease.com

D. van der Heijde

Leiden University Medical Center, Leiden, The

Netherlands

C. Karki · M. Liu · J. D. Greenberg

Corrona, LLC, Waltham, MA, USA

Y. Park

Novartis Pharmaceuticals Corporation, East

Hanover, NJ, USA

J. D. Greenberg

NYU School of Medicine, New York, NY, USA demographic and clinical characteristics of patients with AS who discontinued vs. continued a TNFi by their second follow-up visit in the US-based Corrona Psoriatic Arthritis and Spondyloarthritis (PsA/SpA) Registry.

Methods: All patients aged $\geq 18$ years with AS enrolled in the Corrona PsA/SpA Registry between April 2013 and January 2015 who were receiving or had initiated a TNFi (index therapy) at the time of registry enrollment (baseline) and had $\geq 2$ followup visits were included. Patient demographics, clinical characteristics, and patient-reported outcome scores at baseline were compared between cohorts of patients who discontinued or continued their TNFi by the second follow-up visit.

Results: Of the 155 included patients, 37 (23.9\%) discontinued their index TNFi therapy by the second follow-up visit (mean follow-up, 17.8 months). Patients who discontinued their TNFi were older (mean age, 52.1 vs. 46.6 years; $P=0.04)$, were more likely to be obese $(59.5 \%$ vs. $34.2 \% ; P<0.01$ ), and had worse mean Bath Ankylosing Spondylitis Disease Activity Index and Bath Ankylosing Spondylitis Functional Index scores (4.8 vs. 3.5 and 4.2 vs. 2.8, respectively; $P=0.01$ for both) at baseline than those who continued their TNFi.

Conclusions: The results of this real-world study provide insight into the demographic and clinical characteristics of patients with AS who discontinue vs. continue TNFi therapy in US clinical practice.

Funding: Corrona, LLC. 
Plain Language Summary: Plain language summary available for this article.

Keywords: Ankylosing spondylitis; Biological therapy; Registries; Spondyloarthropathy; Tumor necrosis factor inhibitors

\section{PLAIN LANGUAGE SUMMARY}

Tumor necrosis factor inhibitors (TNFis) are effective for improving disease outcomes in patients with ankylosing spondylitis (AS). However, up to $30 \%$ of patients may discontinue or switch TNFis within the first year of treatment due to lack of treatment effect or side effects. As biologics with new mechanisms of action become available for the treatment of AS, it is important to better understand the characteristics of patients who discontinue or have an inadequate response to TNFis to help inform treatment choices regarding initiating or switching to a biologic therapy.

This study compared demographic and clinical characteristics of patients with AS who discontinued vs continued a TNFi by their second follow-up visit in the US-based Corrona Psoriatic Arthritis and Spondyloarthritis (PsA/SpA) Registry. Approximately one-quarter of patients discontinued their TNFi by the second followup visit; the most commonly reported reasons for discontinuation were lack of effect and side effects. Patients who discontinued their TNFi were older, were more likely to be obese, and had higher disease activity than those who continued their TNFi. These results may help inform treatment decisions regarding initiating or switching to a TNFi in patients with active AS in US clinical practice. Additional studies are needed to evaluate the characteristics of patients who respond to TNFis compared with those who have an inadequate response.

\section{INTRODUCTION}

Ankylosing spondylitis (AS) is a chronic, immune-mediated rheumatic disease that may cause destruction and fusion of the spinal vertebrae and is defined by structural changes on radiographs in the sacroiliac joints [1]. Current estimates indicate that AS affects $0.20-0.55 \%$ of the general population in the United States $[2,3]$. AS occurs more frequently in male patients than in female patients, with disease onset typically occurring in the late teens through 40 years of age [4]. AS is a systemic disorder that can affect the axial skeleton, peripheral joints, entheses, eyes, skin, intestine, and cardiovascular system $[1,4,5]$. Patients with AS may suffer from extra-articular manifestations such as uveitis, inflammatory bowel disease, and psoriasis, and have an increased risk of comorbidities, including hypertension, hyperlipidemia, diabetes, peptic ulcers, headaches, depression, cancer, osteoporosis, and other cardiovascular, pulmonary, renal, and neurological complications, compared with the general population [6-10].

The goals of treatment in patients with AS are to reduce symptoms of pain, stiffness, and fatigue; maintain spinal flexibility and normal posture; reduce functional limitations; maintain work productivity; and decrease complications of the disease $[11,12]$. Current treatment guidelines recommend nonsteroidal anti-inflammatory drugs (NSAIDs) as first-line therapy in patients with active AS $[11,12]$. In patients with active AS despite NSAID treatment, use of a biologic is recommended; current practice suggests use of a tumor necrosis factor inhibitor (TNFi) as the first biologic $[11,12]$. Currently, there are five TNFis approved for the treatment of AS in the United States: adalimumab, certolizumab pegol, etanercept, golimumab, and infliximab [11].

The effectiveness of TNFis in improving clinical and patient-reported outcomes (PROs) in patients with AS has been demonstrated in randomized controlled trials [13-25]. Results from several real-world observational studies support the effectiveness of TNFis in the treatment of AS in routine clinical practice [26-30]. However, prior studies found that approximately $30 \%$ of patients discontinued or switched TNFis within the first year of treatment due to lack of treatment effect or adverse events $[31,32]$. Ineffective management and treatment of AS can lead to continued structural progression resulting in loss of spinal mobility, chronic 
pain and fatigue, and functional disability, causing decreased quality of life and work productivity [33]. Patients may also discontinue or switch TNFis for nonmedical reasons, such as economic factors (e.g., cost of TNFi, loss or change in insurance or job) or patient preference [34]. Some evidence suggests that the efficacy of a subsequent TNFi may decrease compared with that of the initial TNFi in patients who switch TNFis due to an inadequate response [35-37]. As biologics with alternative mechanisms of action become available for the treatment of AS, it is important to better understand the characteristics of patients who discontinue or have an inadequate response to TNFis to help inform treatment choices regarding initiating or switching to a biologic therapy.

Few real-world studies have evaluated the persistency of TNFi use in patients with AS, and most prior studies have been conducted outside the United States. Limited data are available regarding the demographic and clinical characteristics of patients with AS who discontinue TNFi therapy compared with those who continue TNFi therapy in real-world clinical settings in the United States. The objective of this study was to compare patient characteristics in patients with AS who discontinued vs. continued a TNFi therapy by their second follow-up visit in the US-based Corrona Psoriatic Arthritis and Spondyloarthritis (PsA/SpA) Registry.

\section{METHODS}

\section{Study Population}

The Corrona PsA/SpA Registry is a large, independent, prospective, observational cohort of patients diagnosed with PsA or SpA by a rheumatologist. The registry includes patients recruited by 40 participating rheumatologists from 30 private and academic practice sites across 20 states in the United States. As of June 30, 2017, data on approximately 2386 patients with PsA/SpA had been collected. The Corrona PsA/SpA Registry includes information on 9700 patient visits, with a mean duration of followup of 2.6 years (median, 2.8 years).
This study included all patients aged $\geq 18$ years enrolled in the Corrona PsA/ SpA Registry between April 2013 and January 2015 who were diagnosed with AS and fulfilled the 1984 modified New York criteria [38] according to the treating rheumatologist, were receiving or had initiated a TNFi (index therapy) at registry enrollment (baseline), and had $\geq 2$ follow-up visits. Patients were assigned to a cohort based on discontinued or continued use of their index TNFi by the second follow-up visit (at approximately 18 months). Patients in the "continued" cohort were those who were still on their index TNFi at the second follow-up visit. Patients in the "discontinued" cohort were those who switched from their index TNFi to a different TNFi or discontinued their index TNFi without switching by the second follow-up visit.

All participating investigators were required to obtain full board approval for conducting noninterventional research involving human participants with a limited data set. The Corrona PsA/SpA Registry and its investigators have been reviewed and approved by a central institutional review board (IRB; New England Independent Review Board, NEIRB No. 120160070). For academic investigative sites that did not receive a waiver to use the central IRB, full board approval was obtained from the respective governing IRBs. All research was conducted in compliance with the Declaration of Helsinki of 1964 and all later amendments. All registry participants were required to provide written informed consent and authorization prior to participating.

\section{Study Assessments}

Data were collected using questionnaires from patients and their treating rheumatologists at office visits. Data collected at baseline included demographics (age, sex, race, and body mass index), clinical characteristics (symptom duration, human leukocyte antigen B27 positivity, family history of SpA, history of comorbidities, and prior medication use), clinical features (presence of enthesitis, Spondyloarthritis Research Consortium of Canada Enthesitis 
Index score [0-16], presence of dactylitis, 68 tender joint count, and 66 swollen joint count), laboratory measurements (C-reactive protein [CRP] and erythrocyte sedimentation rate [ESR]), disease activity scores (Bath Ankylosing Spondylitis Disease Activity Index [BASDAI; 0-10], Bath Ankylosing Spondylitis Functional Index [BASFI; 0-10], spinal mobility, and Ankylosing Spondylitis Disease Activity Score), and PRO scores (pain [visual analog scale (VAS), 0-100], fatigue [VAS, 0-100], morning stiffness, Health Assessment Questionnaire for the Spondyloarthropathies [0-3], EQ-5D [0-1], EQVAS [0-100], and Work Productivity and Activity Impairment [WPAI] questionnaire).

Provider-reported reasons for discontinuation or switch of the index TNFi were collected for patients in the discontinued cohort. Potential reasons for discontinuation or switch included lack of effect (inadequate response or failure to maintain response), side effects (serious or minor or fear of side effects), doing well (remission or similar events), social reasons (cost, patient preference, or frequency of administration), and other.

\section{Statistical Analysis}

Categorical variables were summarized using frequency counts and percentages. Continuous variables were summarized using the number of observations, mean, and standard deviation. Reasons for discontinuation or switch of the index TNFi were summarized descriptively. Baseline demographics, clinical characteristics, and PRO scores were compared between the discontinued and continued cohorts using $\chi^{2}$ tests or Fisher's exact test for categorical variables and $t$ tests for continuous variables. All statistical analyses were performed using Stata version 14 (StataCorp LLC).

\section{RESULTS}

Of 353 patients with AS enrolled in the Corrona PsA/SpA Registry during the study period, 155 were receiving $(n=134)$ or had initiated $(n=21)$ a TNFi at enrollment and had $\geq 2$ follow-up visits and were included in the analyses (Fig. 1). Overall, most patients were male $(73.5 \%)$ and white $(94.0 \%)$, with a mean (SD) time from symptom onset of 18.5 (12.5) years (Table 1). The majority of patients had prior biologic use $(90.3 \%)$.

The mean (SD) time to the second follow-up visit was 17.8 (7.2) months (median [interquartile range], 15.4 [12.6-20.5] months). At the second follow-up visit, 118 patients $(76.1 \%)$ were still receiving their index TNFi and 37 patients $(23.9 \%)$ had discontinued their index

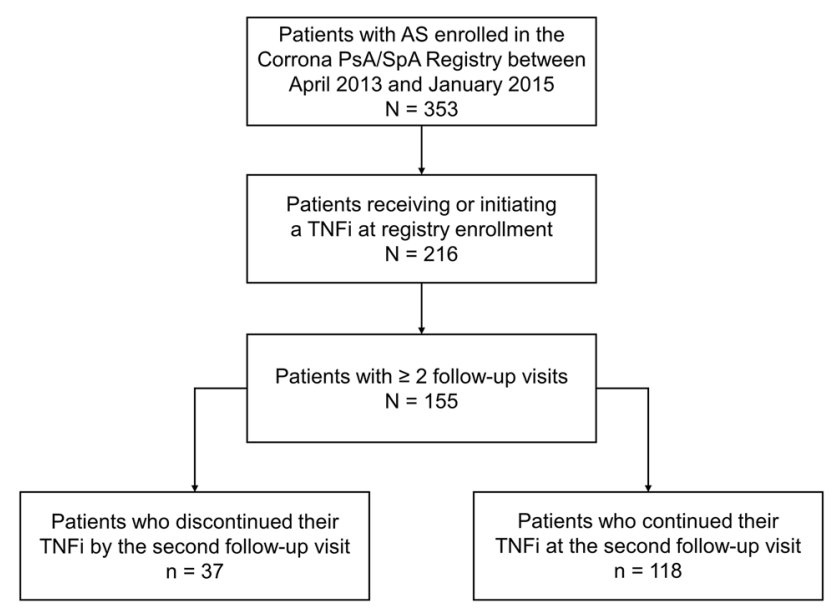

Fig. 1 Study flowchart: patients with AS who continued vs. discontinued TNFi therapy by the second follow-up visit in the Corrona Psoriatic Arthritis and
Spondyloarthritis Registry. $A S$ ankylosing spondylitis, $P s A$ psoriatic arthritis, $S p A$ spondyloarthritis, $T N F i$ tumor necrosis factor inhibitor 
Table 1 Baseline demographics and defining clinical characteristics of all patients with AS who continued vs. discontinued index TNFi therapy by the second follow-up visit

\begin{tabular}{|c|c|c|c|c|}
\hline Characteristic $^{a}$ & $\begin{array}{l}\text { Overall, } \\
N=155\end{array}$ & $\begin{array}{l}\text { Continued TNFi, } \\
n=118\end{array}$ & $\begin{array}{l}\text { Discontinued } \\
\text { TNFi, } n=37\end{array}$ & $P$ value \\
\hline Age, years & $47.9(14.1)$ & $46.6(13.8)$ & $52.1(14.5)$ & 0.04 \\
\hline Male, $n(\%)$ & $114(73.5)$ & $87(73.7)$ & $27(73.0)$ & 0.93 \\
\hline \multicolumn{5}{|l|}{ Race, $n(\%)$} \\
\hline White & $140(94.0)$ & $108(94.7)$ & $32(91.4)$ & 0.13 \\
\hline Asian & $3(2.0)$ & $3(2.6)$ & 0 & \\
\hline Black & $2(1.3)$ & 0 & $2(5.7)$ & \\
\hline Pacific Islander & 0 & 0 & 0 & \\
\hline Mixed race & $3(2.0)$ & $2(1.8)$ & $1(2.9)$ & \\
\hline Other & $1(0.7)$ & $1(0.9)$ & 0 & \\
\hline BMI, $\mathrm{kg} / \mathrm{m}^{2}$ & $29.4(6.6)$ & $28.3(5.8)$ & $32.9(7.8)$ & $<0.001$ \\
\hline \multicolumn{5}{|l|}{ BMI (in $\mathrm{kg} / \mathrm{m}^{2}$ ) classification, $n(\%)$} \\
\hline Normal/underweight $(<25.0)$ & $39(25.8)$ & $37(32.5)$ & $2(5.4)$ & $<0.001$ \\
\hline Overweight $(25.0$ to $<30.0)$ & $51(33.8)$ & $38(33.3)$ & $13(35.1)$ & \\
\hline Obese $(\geq 30.0)$ & $61(40.4)$ & $39(34.2)$ & $22(59.5)$ & \\
\hline Time from symptom onset, years & $18.5(12.5)$ & $18.5(13.0)$ & $18.4(11.1)$ & 0.99 \\
\hline Time from diagnosis, years & $11.9(11.7)$ & $12.1(12.3)$ & $11.1(9.9)$ & 0.67 \\
\hline \multicolumn{5}{|l|}{ HLA-B27 } \\
\hline $\begin{array}{l}\text { Patients with available HLA-B27 test result, } \\
n(\%)\end{array}$ & $108(69.7)$ & $81(68.6)$ & $27(73.0)$ & 0.62 \\
\hline $\begin{array}{l}\text { Positive test result (among patients with available } \\
\text { test results), } n(\%)\end{array}$ & $80(74.1)$ & $60(74.1)$ & $20(74.1)$ & $>0.99$ \\
\hline Family history of SpA, $n(\%)$ & $23(14.8)$ & $19(16.1)$ & $4(10.8)$ & 0.43 \\
\hline \multicolumn{5}{|l|}{ History of comorbidities, $n$ (\%) } \\
\hline Cardiovascular disease $^{\mathrm{b}}$ & $18(11.6)$ & $15(12.7)$ & $3(8.1)$ & 0.57 \\
\hline Serious infection ${ }^{c}$ & $11(7.1)$ & $8(6.8)$ & $3(8.1)$ & 0.73 \\
\hline Diabetes mellitus & $11(7.1)$ & $9(7.6)$ & $2(5.4)$ & $>0.99$ \\
\hline Any cancer ${ }^{\mathrm{d}}$ & $10(6.5)$ & $7(5.9)$ & $3(8.1)$ & 0.70 \\
\hline Psoriasis & $10(6.5)$ & $7(5.9)$ & $3(8.1)$ & 0.64 \\
\hline History of bDMARD use, $n(\%)^{\mathrm{e}}$ & $140(90.3)$ & $108(91.5)$ & $32(86.5)$ & 0.37 \\
\hline
\end{tabular}


Table 1 continued

\begin{tabular}{|c|c|c|c|c|}
\hline Characteristic $^{\mathbf{a}}$ & $\begin{array}{l}\text { Overall, } \\
N=155\end{array}$ & $\begin{array}{l}\text { Continued TNFi, } \\
n=118\end{array}$ & $\begin{array}{l}\text { Discontinued } \\
\text { TNFi, } n=37\end{array}$ & $P$ value \\
\hline \multicolumn{5}{|l|}{ No. prior bDMARDs, $n(\%)^{\mathrm{e}}$} \\
\hline 0 & $15(9.7)$ & $10(8.5)$ & $5(13.5)$ & 0.66 \\
\hline 1 & $99(63.9)$ & $76(64.4)$ & $23(62.2)$ & \\
\hline$\geq 2$ & $41(26.5)$ & $32(27.1)$ & $9(24.3)$ & \\
\hline History of cDMARD use, $n(\%)^{\mathrm{f}}$ & $55(35.5)$ & $39(33.1)$ & $16(43.2)$ & 0.26 \\
\hline \multicolumn{5}{|l|}{ No. prior csDMARDs, $n(\%)^{\mathrm{f}}$} \\
\hline 0 & $128(82.6)$ & $96(81.4)$ & $32(86.5)$ & 0.37 \\
\hline 1 & $21(13.5)$ & $16(13.6)$ & $5(13.5)$ & \\
\hline$\geq 2$ & $6(3.9)$ & $6(5.1)$ & 0 & \\
\hline \multicolumn{5}{|l|}{ Current medication use, $n(\%)$} \\
\hline TNFi only & $58(37.4)$ & $45(38.1)$ & $13(35.2)$ & 0.41 \\
\hline TNFi + NSAID & $62(40.0)$ & $50(42.4)$ & $12(32.4)$ & \\
\hline TNFi + csDMARD & $18(11.6)$ & $12(10.2)$ & $6(16.2)$ & \\
\hline TNFi + csDMARD + NSAID & $17(11.0)$ & $11(9.3)$ & $6(16.2)$ & \\
\hline
\end{tabular}

a All values were calculated based on available data and are presented as "mean (SD)" unless otherwise stated. All variables had $<20 \%$ missing data except for symptom duration $(n=117)$

b Combined histories of myocardial infarction, acute coronary syndrome, coronary artery disease, congestive heart failure, peripheral artery disease, coronary revascularization procedure, ventricular arrhythmia, cardiac arrest, unstable angina, stroke, transient ischemic attack, pulmonary embolism, carotid artery disease, deep vein thrombosis, or other cardiovascular event c Includes infections that led to hospitalization or intravenous antibiotics: joint/bursa, cellulitis, sinusitis, diverticulitis, sepsis, pneumonia, bronchitis, gastroenteritis, meningitis, urinary tract infection, upper respiratory tract infection, or infection of other specified site

d Excludes nonmelanoma of the skin

e Prior bDMARD use may include abatacept, adalimumab, anakinra, certolizumab pegol, etanercept, golimumab, infliximab, rituximab, tocilizumab, and/or ustekinumab

${ }^{f}$ Prior csDMARD use may include hydroxychloroquine, leflunomide, methotrexate, and/or sulfasalazine

$A S$ ankylosing spondylitis, $b D M A R D$ biologic disease-modifying antirheumatic drug, $B M I$ body mass index, $c s D M A R D$ conventional synthetic disease-modifying antirheumatic drug, HLA-B27 human leukocyte antigen B27, NSAID nonsteroidal anti-inflammatory drug, $S p A$ spondyloarthritis, $T N F i$ tumor necrosis factor inhibitor

TNFi, including 24 who switched to a different biologic (65\% of patients who discontinued). Of the 37 patients who discontinued or switched their index TNFi by the second follow-up visit, 18 patients had 19 provider-reported reasons for discontinuation. Reasons for discontinuation of the index TNFi were lack of effect $(n=6)$, side effects $(n=4)$, social reasons $(n=2)$, doing well $(n=1)$, and other $(n=6[1$ temporary interruption, 5 unspecified]).

Patients who discontinued their index TNFi by the second follow-up visit were older (mean [SD] age, 52.1 [14.5] vs. 46.6 [13.8] years; $P=0.04$ ), had a higher body mass index (mean [SD], 32.9 [7.8] vs. $\left.28.3[5.8] \mathrm{kg} / \mathrm{m}^{2} ; P<0.001\right)$, and were more likely to be obese $(60 \%$ vs. $34 \%$; 
Table 2 Baseline clinical features and measures of disease activity, physical function, and spinal mobility of all patients with AS who continued vs. discontinued index TNFi therapy by the second follow-up visit

\begin{tabular}{|c|c|c|c|c|}
\hline Characteristic $^{\mathrm{a}}$ & $\begin{array}{l}\text { Overall, } \\
N=155\end{array}$ & $\begin{array}{l}\text { Continued TNFi, } \\
n=118\end{array}$ & $\begin{array}{l}\text { Discontinued } \\
\text { TNFi, } n=37\end{array}$ & $P$ value \\
\hline Enthesitis, $n(\%)$ & $45(29.0)$ & $34(28.8)$ & $11(29.7)$ & 0.92 \\
\hline $\begin{array}{l}\text { SPARCC Enthesitis Index score (1-16) among } \\
\text { patients with enthesitis }\end{array}$ & $3.5(2.8)$ & $3.6(2.9)$ & $3.2(2.6)$ & 0.67 \\
\hline Dactylitis, $n(\%)$ & $8(5.2)$ & $8(6.8)$ & 0 & 0.10 \\
\hline $\begin{array}{l}\text { Dactylitis count (1-20) among patients with } \\
\text { dactylitis }\end{array}$ & $3.3(4.0)$ & $3.3(4.0)$ & 0 & 0.49 \\
\hline History of dactylitis, $n$ (\%) & $6(3.9)$ & $4(3.4)$ & $2(5.4)$ & 0.58 \\
\hline Tender joint count $(0-68)$ & $2.5(5.8)$ & $2.6(6.3)$ & $1.9(4.0)$ & 0.54 \\
\hline Swollen joint count $(0-66)$ & $0.4(1.4)$ & $0.4(1.4)$ & $0.5(1.2)$ & 0.74 \\
\hline Patients with swollen joint count $\geq 1, n(\%)$ & $25(16.5)$ & $17(14.8)$ & $8(21.6)$ & 0.33 \\
\hline BASDAI score $(0-10)$ & $3.8(2.5)$ & $3.5(2.4)$ & $4.8(2.6)$ & 0.01 \\
\hline BASDAI score $\geq 4, n(\%)$ & $69(44.5)$ & $48(42.5)$ & $21(60.0)$ & 0.07 \\
\hline BASFI score $(0-10)$ & $3.2(2.9)$ & $2.8(2.7)$ & $4.2(3.1)$ & 0.01 \\
\hline \multicolumn{5}{|l|}{ Spinal mobility measures } \\
\hline Occiput-to-wall distance, $\mathrm{cm}$ & $4.3(6.9)$ & $4.4(7.1)$ & $4.0(6.3)$ & 0.76 \\
\hline $\begin{array}{l}\text { Lateral lumbar flexion (average of right and left), } \\
\mathrm{cm}\end{array}$ & $22.8(18.9)$ & $23.6(19.6)$ & $20.1(16.4)$ & 0.39 \\
\hline ASDAS & $1.9(0.8)$ & $1.9(0.8)$ & $1.8(0.7)$ & 0.64 \\
\hline \multicolumn{5}{|l|}{ ASDAS disease activity, $n(\%)$} \\
\hline Inactive $(<1.3)$ & $21(21.0)$ & $15(19.7)$ & $6(25.0)$ & 0.72 \\
\hline Moderate $(\geq 1.3$ to $<2.1)$ & $45(45.0)$ & $35(46.1)$ & $10(41.7)$ & \\
\hline High $(\geq 2.1$ to $<3.5)$ & $31(31.0)$ & $23(30.3)$ & $8(33.3)$ & \\
\hline Very high $(\geq 3.5)$ & $3(3.0)$ & $3(4.0)$ & 0 & \\
\hline $\mathrm{CRP}, \mathrm{mg} / \mathrm{l}$ & $2.1(5.8)$ & $2.5(6.5)$ & $1.0(2.1)$ & 0.22 \\
\hline Elevated CRP, $n(\%)$ & $23(14.8)$ & $16(13.6)$ & $7(18.9)$ & 0.42 \\
\hline $\mathrm{ESR}, \mathrm{mm} / \mathrm{h}$ & $11.2(15.2)$ & $9.8(12.9)$ & $16.2(20.7)$ & 0.08 \\
\hline
\end{tabular}

a All values were calculated based on available data and are presented as "mean (SD)" unless otherwise stated. All variables had $<20 \%$ missing data except for ASDAS $(n=100)$, CRP $(n=109)$, and ESR $(n=99)$

$A S$ ankylosing spondylitis, ASDAS Ankylosing Spondylitis Disease Activity Score, BASDAI Bath Ankylosing Spondylitis Disease Activity Index, BASFI Bath Ankylosing Spondylitis Functional Index, CRP C-reactive protein, ESR erythrocyte sedimentation rate, SPARCC Spondyloarthritis Research Consortium of Canada, TNFi tumor necrosis factor inhibitor 
Table 3 Baseline patient-reported outcome measures of all patients with AS who continued vs. discontinued index TNFi therapy by the second follow-up visit

\begin{tabular}{|c|c|c|c|c|}
\hline Characteristic $^{\mathrm{a}}$ & $\begin{array}{l}\text { Overall, } \\
N=155\end{array}$ & $\begin{array}{l}\text { Continued } \\
\mathrm{TNFi}, n=118\end{array}$ & $\begin{array}{l}\text { Discontinued } \\
\text { TNFi, } n=37\end{array}$ & $P$ value \\
\hline Patient pain score (VAS, 0-100) & $37.3(30.1)$ & $36.2(30.5)$ & $41.1(28.8)$ & 0.42 \\
\hline Patient-reported fatigue score (VAS, 0-100) & $44.9(29.5)$ & $42.7(28.9)$ & $51.9(20.7)$ & 0.10 \\
\hline \multicolumn{5}{|l|}{ Morning stiffness, $n(\%)$} \\
\hline Yes & $132(85.2)$ & $100(84.7)$ & $32(86.5)$ & 0.80 \\
\hline$<30 \mathrm{~min}$ & $33(25.0)$ & $28(28.0)$ & $5(15.6)$ & \\
\hline$\geq 30 \mathrm{~min}$ & $99(75.0)$ & $72(72.0)$ & $27(84.4)$ & \\
\hline HAQ-S score $(0-3)$ & $0.5(0.6)$ & $0.5(0.6)$ & $0.6(0.5)$ & 0.14 \\
\hline EQ-5D score $(0-1)$ & $0.8(0.2)$ & $0.8(0.2)$ & $0.7(0.2)$ & 0.18 \\
\hline EQ-VAS score $(0-100)$ & $69.2(22.9)$ & $70.3(22.4)$ & $65.5(24.5)$ & 0.28 \\
\hline Current employment, $n$ (\%) & $104(68.4)$ & $80(69.0)$ & $24(66.7)$ & 0.80 \\
\hline \multicolumn{5}{|l|}{ WPAI domains } \\
\hline Absenteeism (work time missed), \% & $7.2(18.7)$ & $5.1(13.4)$ & $14.5(29.7)$ & 0.04 \\
\hline $\begin{array}{l}\text { Presenteeism (impairment at work/reduced on-the-job } \\
\text { effectiveness), \% }\end{array}$ & $22.6(23.3)$ & $21.1(21.5)$ & $27.9(28.2)$ & 0.21 \\
\hline $\begin{array}{l}\text { Work productivity loss (overall work impairment/ } \\
\text { absenteeism plus presenteeism), \% }\end{array}$ & $26.1(26.5)$ & $24.3(24.1)$ & $32.1(33.3)$ & 0.23 \\
\hline Activity impairment, \% & $33.0(31.4)$ & $31.9(31.4)$ & $36.3(31.8)$ & 0.46 \\
\hline
\end{tabular}

${ }^{a}$ All values were calculated based on available data and are presented as "mean (SD)" unless otherwise stated $A S$ ankylosing spondylitis, HAQ-S Health Assessment Questionnaire for the Spondyloarthropathies, TNFi tumor necrosis factor inhibitor, VAS visual analog scale, WPAI Work Productivity and Activity Impairment questionnaire

$P<0.001)$ at baseline than patients who continued their index TNFi (Table 1). History of comorbidities and prior and current medication use were comparable between the discontinued and continued cohorts (Table 1).

Baseline clinical characteristics (Table 2) and PRO scores (Table 3 ) were generally comparable between the continued and discontinued cohorts. However, patients who discontinued their index TNFi by the second follow-up visit had higher baseline BASDAI (mean [SD], 4.8 [2.6] vs. 3.5 [2.4]; $P=0.01$ ) and BASFI scores (mean [SD], 4.2 [3.1] vs. 2.8 [2.7]; $P=0.01$ ) than patients who continued their index TNFi (Table 2). Additionally, patients in the discontinued cohort reported higher baseline pain (mean [SD], 41.1 [28.8] vs. 36.2 [30.5]) and fatigue scores (mean [SD], 51.9 [20.7] vs. 42.7 [28.9]) compared with those in the continued cohort, although these differences did not reach statistical significance $(P=0.42$ and 0.10 , respectively) (Table 3). Patients who discontinued their TNFi also reported worse WPAI scores at baseline than those who continued their TNFi; in particular, patients in the discontinued cohort reported a higher percentage of absenteeism (mean [SD], 14.5\% [29.7\%]) compared with those in the continued cohort (mean [SD], 5.1\% [13.4\%]; $P=0.04$ ) (Table 3). 


\section{DISCUSSION}

This real-world study using the US-based Corrona PsA/SpA Registry provides insight into the characteristics of patients with AS who discontinue vs. continue TNFi therapy in routine clinical practice. Of the patients who were receiving or had initiated a TNFi at enrollment in the registry, approximately one quarter discontinued their TNFi by the second follow-up visit (mean time to the second follow-up visit, 17.8 months; median, 15.4 months). The most common provider-reported reasons for discontinuation were lack of efficacy, side effects, and other. Patients who discontinued their TNFi were older, were more likely to be obese, and had higher baseline disease activity than those who continued their TNFi.

Previous observational studies of TNFi discontinuation or switching conducted outside the United States have reported TNFi discontinuation rates of $22-53 \%$ over 1 to 2 years of follow-up among patients with AS [31, 39-43]. The most common provider-reported reasons for discontinuation or switch of a TNFi across studies were lack or loss of efficacy and adverse events [31, 39-43]. In our study, $24 \%$ of patients discontinued or switched their index TNFi over a mean of approximately 18 months of followup. In agreement with previous studies, the most common provider-reported reasons for discontinuation or switching were lack of efficacy and side effects.

Patient factors associated with TNFi discontinuation or switching vary between studies. Several studies have identified female sex as a predictor of TNFi discontinuation and switching $[31,39,40,43-49]$. In a study of patients with rheumatoid arthritis, psoriatic arthritis, and AS who initiated a TNFi in the NORDMARD registry, additional predictors of TNFi discontinuation included higher baseline disease activity as measured by the investigator's global assessment and use of TNFi without a conventional synthetic disease-modifying antirheumatic drug (csDMARD) [40]. An analysis of TNFi-naive patients with AS who initiated a TNFi in the DANBIO registry showed that $\mathrm{CRP}<14 \mathrm{mg} / \mathrm{l}$ and higher fatigue scores were associated with shorter time to TNFi discontinuation [42]. In the Groningen Leeuwarden Ankylosing Spondylitis (GLAS) study, a prospective longitudinal observational study of patients with AS initiating a first TNFi, factors found to be associated with TNFi discontinuation included absence of peripheral arthritis, higher baseline BASDAI score, and lower ESR or CRP level [31]. A prospective, observational study of TNFi-naive patients with AS who initiated a TNFi in the South Swedish Arthritis Treatment Group Register also identified absence of peripheral arthritis as a significant predictor of TNFi discontinuation and showed a trend toward greater likelihood of TNFi discontinuation in patients with lower CRP levels and use of TNFi without a csDMARD; however, no association was found between disease activity measures including BASDAI, BASFI, and investigator's global assessment and the likelihood of TNFi discontinuation [43]. With respect to switching, previous studies have identified older age, higher disease activity, greater symptom burden, higher ESR, complete ankylosis, and presence of enthesitis as predictors of TNFi switching [39, 44-49].

In our US-based study, patients with AS who discontinued or switched their index TNFi were older and had higher baseline BASDAI, BASFI, pain, and fatigue scores than those who continued their TNFi. In our study cohort, patients who discontinued or switched their index TNFi were also more likely to be obese and reported greater work productivity and activity impairment than those who continued their TNFi. In contrast with previous studies, the proportion of patients who were female, the proportion of patients who were receiving a TNFi with a csDMARD, ESR, and CRP levels were comparable between patients who discontinued vs. continued their index TNFi. The variation in patient factors that are predictive of TNFi discontinuation may be influenced by demographics, treatment history, and choice of TNFi among patients included in a specific study population.

Limited data are available regarding TNFi discontinuation in patients with AS seen in clinical practice in the United States. Prior studies using US healthcare claims data have 
evaluated persistency, treatment patterns, healthcare resource utilization, and healthcareassociated costs of biologic treatment in patients with rheumatoid arthritis, psoriasis, psoriatic arthritis, and AS; these studies found overall biologic discontinuation rates of $11-35 \%[32,34,50-52]$. However, this is the first study to compare baseline characteristics between US patients with AS who discontinued their TNFi and those who continued their TNFi, presenting important insights into the characteristics of patients who discontinue TNFis and the reasons for TNFi discontinuation in routine clinical practice in the United States.

A general limitation of observational studies is the concern that patients enrolled in registries may not be representative of patients seen elsewhere in general practice. Patients in this study are routinely seen and treated by rheumatologists voluntarily participating in the Corrona PsA/SpA Registry; these patients may not be representative of all patients with AS in the United States, many of whom are not being treated by a rheumatologist. The small sample size necessitated the pooling of TNFis for analysis; therefore, no conclusions can be drawn regarding the persistency of specific TNFi agents among patients with AS. Finally, only about half of the patients (18 of 37 ) who discontinued their index TNFi had provider-reported reasons for discontinuing or switching, providing limited information on the reasons for TNFi discontinuation in this study population.

\section{CONCLUSIONS}

This real-world study provides insight into the demographic and clinical characteristics of US patients with AS who discontinue vs. continue TNFi therapy in routine clinical practice. Approximately one-quarter of patients discontinued their TNFi by the second follow-up visit; the most common provider-reported reasons for discontinuation were lack of effect and side effects. Patients who discontinued their TNFi were older, were more likely to be obese, and had higher disease activity than those who continued their TNFi. This study helps to address a knowledge gap by contributing information on the characteristics of patients who discontinue TNFis and the reasons for TNFi discontinuation in the United States. These results may help inform treatment decisions regarding initiating or switching to a TNFi in patients with active AS in US clinical practice. Additional studies are needed to evaluate the characteristics of patients who respond to TNFis compared with those who have an inadequate response.

\section{ACKNOWLEDGMENTS}

Funding. This study was sponsored by Corrona, LLC. Corrona has been supported through contracted subscriptions in the last 2 years by AbbVie, Amgen, Boehringer Ingelheim, BristolMyers Squibb, Celgene, Crescendo, Eli Lilly and Company, Genentech, Gilead, GSK, Horizon Pharma USA, Janssen, Momenta Pharmaceuticals, Novartis, Pfizer Inc., Regeneron, Roche, Merck, UCB, and Valeant. The design and study conduct were a collaborative effort between Corrona and Novartis, and financial support for the study was provided by Novartis. Novartis participated in the interpretation of data and review and approval of the manuscript. All authors had full access to all of the data in this study and take complete responsibility for the integrity of the data and accuracy of the data analysis. Article processing charges were funded by Novartis Pharmaceuticals Corporation, East Hanover, NJ.

Medical Writing and Editorial Assistance. Support for third-party writing assistance for this manuscript, furnished by Elizabeth Ohneck, $\mathrm{PhD}$, of Health Interactions, Inc, was provided by Novartis Pharmaceuticals Corporation, East Hanover, NJ.

Authorship. All named authors meet the International Committee of Medical Journal Editors (ICMJE) criteria for authorship for this article, take responsibility for the integrity of the work as a whole and have given their approval for this version to be published. 
Disclosures. Philip J. Mease has received research grants from Celgene, Novartis, AbbVie, Amgen, Bristol-Myers Squibb, Lilly, Pfizer, and UCB; consulting fees from Celgene, Corrona, Novartis, AbbVie, Amgen, Bristol-Myers Squibb, Crescendo, Genentech, Janssen, Lilly, Merck, Pfizer, and UCB; and speakers bureau fees from AbbVie, Amgen, Bristol-Myers Squibb, Crescendo, Celgene, Genentech, Janssen, Pfizer, and UCB. Désirée van der Heijde has received consulting fees from AbbVie, Amgen, Astellas, AstraZeneca, Bristol-Myers Squibb, Boehringer Ingelheim, Celgene, Daiichi Sankyo, Eli Lilly, Galapagos, Janssen, Merck, Novartis, Pfizer, Roche, Sanofi, and UCB and is the Director of Imaging Rheumatology BV, the Netherlands. Chitra Karki was an employee of Corrona at the time of this study, and is currently an employee of Ipsos Healthcare, Boston, MA. Mei Liu is an employee of Corrona. Yujin Park is an employee of Novartis. Jeffrey D. Greenberg is an employee and shareholder of Corrona and has received consulting fees from Eli Lilly, Genentech, Janssen, Novartis, and Pfizer.

Compliance with Ethics Guidelines. Ethics approvals for this study were obtained from a central institutional review board (IRB; New England Independent Review Board, NEIRB No. 120160070). For academic investigative sites that did not receive a waiver to use the central IRB, full board approval was obtained from the respective governing IRBs and documentation of approval was submitted to the Sponsor prior to initiating any study procedures. All procedures performed in studies involving human participants were in accordance with the ethical standards of the institutional and/or national research committee and with the 1964 Helsinki Declaration and its later amendments or comparable ethical standards. Informed consent was obtained from all individual participants included in the study.

Data Availability. The Corrona dataset is based on a large US multicenter study adhering to a number of institutional review boards, with complex logistics. Patients did not provide consent to raw data sharing during the data collection for this purpose, and the Corrona data sharing policies do not permit raw data sharing for this purpose. An aggregated limited dataset from the current analyses is available to qualified investigators with an approved protocol. Data requests may be sent to Corrona, represented by Dr. Jeffrey D. Greenberg, MD, MPH, NYU School of Medicine, New York, NY; e-mail: jgreenberg@corrona.org.

Open Access. This article is distributed under the terms of the Creative Commons Attribution-NonCommercial 4.0 International License (http://creativecommons.org/licenses/ by-nc/4.0/), which permits any noncommercial use, distribution, and reproduction in any medium, provided you give appropriate credit to the original author(s) and the source, provide a link to the Creative Commons license, and indicate if changes were made.

\section{REFERENCES}

1. Ghasemi-Rad M, Attaya H, Lesha E, et al. Ankylosing spondylitis: a state of the art factual backbone. World J Radiol. 2015;7:236-52.

2. Reveille JD. Epidemiology of spondyloarthritis in North America. Am J Med Sci. 2011;341:284-6.

3. Reveille JD, Weisman MH. The epidemiology of back pain, axial spondyloarthritis and HLA-B27 in the United States. Am J Med Sci. 2013;345:431-6.

4. Shaikh SA. Ankylosing spondylitis: recent breakthroughs in diagnosis and treatment. J Can Chiropr Assoc. 2007;51:249-60.

5. Stolwijk C, van Tubergen A, Castillo-Ortiz JD, Boonen A. Prevalence of extra-articular manifestations in patients with ankylosing spondylitis: a systematic review and meta-analysis. Ann Rheum Dis. $2015 ; 74: 65-73$.

6. Bremander A, Petersson IF, Bergman S, Englund M. Population-based estimates of common comorbidities and cardiovascular disease in ankylosing spondylitis. Arthritis Care Res (Hoboken). 2011;63:550-6.

7. Kang JH, Chen YH, Lin HC. Comorbidity profiles among patients with ankylosing spondylitis: a nationwide population-based study. Ann Rheum Dis. 2010;69:1165-8. 
8. Mercieca C, van der Horst-Bruinsma IE, Borg AA. Pulmonary, renal and neurological comorbidities in patients with ankylosing spondylitis; implications for clinical practice. Curr Rheumatol Rep. 2014;16:434.

9. Meesters JJ, Bremander A, Bergman S, Petersson IF, Turkiewicz A, Englund M. The risk for depression in patients with ankylosing spondylitis: a populationbased cohort study. Arthritis Res Ther. 2014;16:418.

10. Sun LM, Muo CH, Liang JA, Chang SN, Sung FC, $\mathrm{Kao} \mathrm{CH}$. Increased risk of cancer for patients with ankylosing spondylitis: a nationwide populationbased retrospective cohort study. Scand J Rheumatol. 2014;43:301-6.

11. van der Heijde D, Ramiro S, Landewe R, et al. 2016 update of the ASAS-EULAR management recommendations for axial spondyloarthritis. Ann Rheum Dis. 2017;76:978-91.

12. Ward MM, Deodhar A, Akl EA, et al. American College of Rheumatology/Spondylitis Association of America/Spondyloarthritis Research and Treatment Network 2015 recommendations for the treatment of ankylosing spondylitis and nonradiographic axial spondyloarthritis. Arthritis Rheumatol. 2016;68:282-98.

13. Barkham N, Coates LC, Keen H, et al. Double-blind placebo-controlled trial of etanercept in the prevention of work disability in ankylosing spondylitis. Ann Rheum Dis. 2010;69:1926-8.

14. Brandt J, Khariouzov A, Listing J, et al. Six-month results of a double-blind, placebo-controlled trial of etanercept treatment in patients with active ankylosing spondylitis. Arthritis Rheum. 2003;48:1667-75.

15. Braun J, Brandt J, Listing J, et al. Treatment of active ankylosing spondylitis with infliximab: a randomised controlled multicentre trial. Lancet. 2002;359:1187-93.

16. Calin A, Dijkmans BA, Emery P, et al. Outcomes of a multicentre randomised clinical trial of etanercept to treat ankylosing spondylitis. Ann Rheum Dis. 2004;63:1594-600.

17. Davis JC Jr, Van Der Heijde D, Braun J, et al. Recombinant human tumor necrosis factor receptor (etanercept) for treating ankylosing spondylitis: a randomized, controlled trial. Arthritis Rheum. 2003;48:3230-6.

18. Dougados M, van der Heijde D, Sieper J, et al. Symptomatic efficacy of etanercept and its effects on objective signs of inflammation in early nonradiographic axial spondyloarthritis: a multicenter, randomized, double-blind, placebo-controlled trial. Arthritis Rheumatol. 2014;66:2091-102.

19. Inman RD, Davis JC Jr, Heijde D, et al. Efficacy and safety of golimumab in patients with ankylosing spondylitis: results of a randomized, double-blind, placebo-controlled, phase III trial. Arthritis Rheum. 2008;58:3402-12.

20. Landewe R, Braun J, Deodhar A, et al. Efficacy of certolizumab pegol on signs and symptoms of axial spondyloarthritis including ankylosing spondylitis: 24-week results of a double-blind randomised placebo-controlled phase 3 study. Ann Rheum Dis. 2014;73:39-47.

21. Sieper J, van der Heijde D, Dougados M, et al. Efficacy and safety of adalimumab in patients with non-radiographic axial spondyloarthritis: results of a randomised placebo-controlled trial (ABILITY-1). Ann Rheum Dis. 2013;72:815-22.

22. Sieper J, van der Heijde D, Dougados M, et al. A randomized, double-blind, placebo-controlled, sixteen-week study of subcutaneous golimumab in patients with active nonradiographic axial spondyloarthritis. Arthritis Rheumatol. 2015;67:2702-12.

23. Sieper J, Landewe R, Rudwaleit M, et al. Effect of certolizumab pegol over ninety-six weeks in patients with axial spondyloarthritis: results from a phase III randomized trial. Arthritis Rheumatol. 2015;67:668-77.

24. van der Heijde D, Dijkmans B, Geusens P, et al. Efficacy and safety of infliximab in patients with ankylosing spondylitis: results of a randomized, placebo-controlled trial (ASSERT). Arthritis Rheum. 2005;52:582-91.

25. van der Heijde D, Kivitz A, Schiff MH, et al. Efficacy and safety of adalimumab in patients with ankylosing spondylitis: results of a multicenter, randomized, double-blind, placebo-controlled trial. Arthritis Rheum. 2006;54:2136-46.

26. Coates LC, Cawkwell LS, Ng NW, et al. Real life experience confirms sustained response to longterm biologics and switching in ankylosing spondylitis. Rheumatology (Oxford). 2008;47:897-900.

27. Nikas SN, Alamanos Y, Voulgari PV, Pliakou XI, Papadopoulos CG, Drosos AA. Infliximab treatment in ankylosing spondylitis: an observational study. Ann Rheum Dis. 2005;64:940-2.

28. Prince DS, McGuigan LE, McGirr EE. Working life and physical activity in ankylosing spondylitis pre and post anti-tumor necrosis factor-alpha therapy. Int J Rheum Dis. 2014;17:165-72. 
29. Rahman P, Choquette D, Bensen WG, et al. Biologic Treatment Registry Across Canada (BioTRAC): a multicentre, prospective, observational study of patients treated with infliximab for ankylosing spondylitis. BMJ Open. 2016;6(e009661):2015-009661.

30. Spadaro A, Lubrano E, Marchesoni A, et al. Remission in ankylosing spondylitis treated with antiTNF-alpha drugs: a national multicentre study. Rheumatology (Oxford). 2013;52:1914-9.

31. Arends S, Brouwer E, van der Veer E, et al. Baseline predictors of response and discontinuation of tumor necrosis factor-alpha blocking therapy in ankylosing spondylitis: a prospective longitudinal observational cohort study. Arthritis Res Ther. 2011;13:R94.

32. Bonafede M, Fox KM, Watson C, Princic N, Gandra SR. Treatment patterns in the first year after initiating tumor necrosis factor blockers in real-world settings. Adv Ther. 2012;29:664-74.

33. Sieper J, Rudwaleit M. Early referral recommendations for ankylosing spondylitis (including pre-radiographic and radiographic forms) in primary care. Ann Rheum Dis. 2005;64:659-63.

34. Yeaw J, Watson C, Fox KM, Schabert VF, Goodman S, Gandra SR. Treatment patterns following discontinuation of adalimumab, etanercept, and infliximab in a US managed care sample. Adv Ther. 2014;31:410-25.

35. Ciurea A, Exer P, Weber U, et al. Does the reason for discontinuation of a first TNF inhibitor influence the effectiveness of a second TNF inhibitor in axial spondyloarthritis? Results from the Swiss Clinical Quality Management Cohort. Arthritis Res Ther. 2016;18:71.

36. Gomez-Reino JJ, Carmona L, BIOBADASER Group. Switching TNF antagonists in patients with chronic arthritis: an observational study of 488 patients over a four-year period. Arthritis Res Ther. 2006;8:R29.

37. Lie E, van der Heijde D, Uhlig T, et al. Effectiveness of switching between TNF inhibitors in ankylosing spondylitis: data from the NOR-DMARD register. Ann Rheum Dis. 2011;70:157-63.

38. van der Linden S, Valkenburg HA, Cats A. Evaluation of diagnostic criteria for ankylosing spondylitis. A proposal for modification of the New York criteria. Arthritis Rheum. 1984;27:361-8.

39. Deodhar A, Yu D. Switching tumor necrosis factor inhibitors in the treatment of axial spondyloarthritis. Semin Arthritis Rheum. 2017;47:343-50.
40. Heiberg MS, Koldingsnes W, Mikkelsen K, et al. The comparative one-year performance of anti-tumor necrosis factor alpha drugs in patients with rheumatoid arthritis, psoriatic arthritis, and ankylosing spondylitis: results from a longitudinal, observational, multicenter study. Arthritis Rheum. 2008;59:234-40.

41. Heinonen AV, Aaltonen KJ, Joensuu JT, et al. Effectiveness and drug survival of TNF inhibitors in the treatment of ankylosing spondylitis: a prospective cohort study. J Rheumatol. 2015;42:2339-46.

42. Glintborg B, Ostergaard M, Krogh NS, Dreyer L, Kristensen HL, Hetland ML. Predictors of treatment response and drug continuation in 842 patients with ankylosing spondylitis treated with anti-tumour necrosis factor: results from 8 years' surveillance in the Danish nationwide DANBIO registry. Ann Rheum Dis. 2010;69:2002-8.

43. Kristensen LE, Karlsson JA, Englund M, Petersson IF, Saxne T, Geborek P. Presence of peripheral arthritis and male sex predicting continuation of anti-tumor necrosis factor therapy in ankylosing spondylitis: an observational prospective cohort study from the South Swedish Arthritis Treatment Group Register. Arthritis Care Res (Hoboken). 2010;62:1362-9.

44. Dadoun S, Geri G, Paternotte S, Dougados M, Gossec L. Switching between tumour necrosis factor blockers in spondyloarthritis: a retrospective monocentre study of 222 patients. Clin Exp Rheumatol. 2011;29:1010-3.

45. Rosales-Alexander JL, Balsalobre Aznar J, Perez-Vicente S, Magro-Checa C. Drug survival of anti-tumour necrosis factor alpha therapy in spondyloarthropathies: results from the Spanish emAR II study. Rheumatology (Oxford). 2015;54:1459-63.

46. Lee JW, Kang JH, Yim YR, et al. Predictors of switching anti-tumor necrosis factor therapy in patients with ankylosing spondylitis. PLOS ONE. 2015;10:e0131864.

47. Glintborg B, Ostergaard M, Krogh NS, et al. Clinical response, drug survival and predictors thereof in 432 ankylosing spondylitis patients after switching tumour necrosis factor alpha inhibitor therapy: results from the Danish nationwide DANBIO registry. Ann Rheum Dis. 2013;72:1149-55.

48. Gulyas K, Bodnar N, Nagy Z, et al. Real-life experience with switching TNF-alpha inhibitors in ankylosing spondylitis. Eur J Health Econ. 2014;15(Suppl 1):S93-100.

49. Jeong H, Eun YH, Kim IY, et al. Drug survival of tumor necrosis factor alpha inhibitors in patients 
with ankylosing spondylitis in Korea. Korean J Intern Med. 2018;33:407-16.

50. Howe A, Eyck LT, Dufour R, Shah N, Harrison DJ. Treatment patterns and annual drug costs of biologic therapies across indications from the Humana commercial database. J Manag Care Spec Pharm. 2014;20:1236-44.
51. Bonafede M, Fox KM, Watson C, Princic N, Gandra SR. Treatment patterns in the first year after initiating tumor necrosis factor blockers in real-world settings. Adv Ther. 2012;29:664-74.

52. Palmer JB, Li Y, Herrera V, Liao M, Ozturk Z. Treatment patterns and costs for ant-TNF alpha therapy in patients with ankylosing spondylitis. Rheum: Curr Res; 2015. p. S6. 